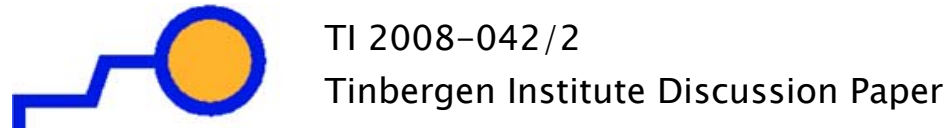 \\ Have Euro Area Government Bond Risk Premia Converged To Their Common State?
}

Lorenzo Pozzil

Guido Wolswijk ${ }^{2}$

' Erasmus University Rotterdam;

2 European Central Bank. 


\section{Tinbergen Institute}

The Tinbergen Institute is the institute for economic research of the Erasmus Universiteit Rotterdam, Universiteit van Amsterdam, and Vrije Universiteit Amsterdam.

Tinbergen Institute Amsterdam

Roetersstraat 31

1018 WB Amsterdam

The Netherlands

Tel.: +31(0)205513500

Fax: $+31(0) 205513555$

Tinbergen Institute Rotterdam

Burg. Oudlaan 50

3062 PA Rotterdam

The Netherlands

Tel.: + $31(0) 104088900$

Fax: $+31(0) 104089031$

Most TI discussion papers can be downloaded at http://www.tinbergen.nl. 


\title{
Have euro area government bond risk premia converged to their common state ?*
}

\author{
Lorenzo Pozzi $\quad$ Guido Wolswijk ${ }^{\ddagger}$
}

December 2008

\begin{abstract}
We derive a model in which a standard international capital asset pricing model (ICAPM) is nested within an ICAPM with market imperfections. In the latter model an idiosyncratic stochastic factor affects the return of risky government bonds (over a risk-free rate) on top of the systematic component that is common to all countries (and that is interacted with a time-varying idiosyncratic "beta"). We introduce asymptotic convergence from the full ICAPM with imperfections to the standard model by multiplying the idiosyncratic factor by convergence operators. The model is then estimated using weekly government bond returns for Belgium, France, Italy, Germany, and the Netherlands over the period 1995-2006. We find that the idiosyncratic components have converged towards zero for all countries over the sample period. By the end of the sample period the government bond markets considered are almost fully efficient, with the exception of Italy.
\end{abstract}

JEL Classifications: E43, G12

Keywords: Government bonds, euro area, risk premia, state space methods

\footnotetext{
${ }^{*}$ Work on this paper was started while the first author was visiting the Fiscal Policies Division of the European Central Bank. The opinions expressed are those of the authors and do not necessarily reflect the views of the ECB.

†Tinbergen Institute and Department of Economics, Erasmus University Rotterdam, pozzi@few.eur.nl, http://people.few.eur.nl/pozzi.

‡European Central Bank, guido.wolswijk@ecb.int
} 


\section{Introduction.}

This paper investigates the integration of the government bond markets in five euro area countries (Belgium, France, Italy, Germany, and the Netherlands) during the period 1995-2006. The existing literature suggests that the correlation of government bond returns between different (euro area) countries has increased in recent years: government bond returns seem to be driven less by countryspecific or local idiosyncratic factors and more by common international factors.

Two related strands of the literature investigate the integration of international government bond markets.

The first strand of the literature focuses on the presence of a common international risk factor in international government bond yield differentials, i.e. the spreads between local yields to maturity versus the yields to maturity of some benchmark country (most often Germany). An early contribution that emphasizes the presence of local and global factors in government bond spreads of high yielders like Italy versus Germany is Favero et al. (1997). Codogno et al. (2003) relate US risk factors (corporate and banking risk) to country-specific default risk for a number of countries among which are Belgium, France, Italy, and the Netherlands. They conclude that the impact of international risk factors is higher in countries with a higher government debt. They also find that, for the year 2002, the liquidity component in the bond spreads is not very important. Bernoth et al. (2004) examine yield spreads of EU countries versus Germany and the United States. They conclude that international risk factors captured by US corporate risk affect spreads, but evidence on the interaction of global risk with local fundamentals or liquidity indicators is mixed. Their results do suggest that the introduction of the euro has decreased liquidity premia in euro area government bond spreads. Favero et al. (2007) argue that the changing risk attitude of international investors interacts with liquidity indicators. Dungey et al. (2000) do not use a proxy for international risk but explicitly filter the common factor out of the government bond spreads through the use of factor analysis. They find a common factor in the long-term bond yield differentials of Australia, Japan, Germany, Canada, and the UK versus the US. Geyer et al. (2004) filter out a common component in the bond spreads of Austria, Belgium, Italy, and Spain versus Germany. They find a significant impact of European risk proxies on the common factor and interpret the common factor as a risk premium that reflects the risk of a failure of EMU that could lead to the reintroduction of exchange rate risks.

The second strand of the literature investigates the presence of a common factor in excess bond 
returns or bond risk premia (i.e. the realized one-period holding return of a long-term government bond in excess of the return of a one-period bond in the same country). Ilmanen (1995) finds that the excess bond returns of the US, Canada, Japan, Germany, France, and the UK are highly correlated over the period 1978-1993. Cappiello et al. (2003) find a high correlation between the returns of government bonds of different countries and argue that the introduction of the euro has lead to near perfect correlation among bond returns within EMU countries. Barr and Priestley (2004) look at the US, UK, Japan, Germany, and Canada and find that one quarter of excess government bond returns is related to local market risk while the remainder is due to world bond market risk. They find no time variation in the level of integration over the period 1986-1996.

In this paper we add to the second strand of the literature. We investigate whether the countryspecific or idiosyncratic components in the excess returns or risk premia of the government bonds of the euro area countries under consideration have converged towards zero. In standard asset pricing models (see e.g. Harvey 1991) such components imply inefficiencies since only systematic common risk should be rewarded. As a result, if the idiosyncratic components have converged towards zero, the excess returns or risk premia have converged towards their common state and the efficiency of the government bond markets under investigation is said to have increased.

The contribution of this paper to the literature is both theoretical and methodological.

Theoretically, we use an international capital asset pricing model (ICAPM) as presented for instance by Harvey (1991) where a representative global investor invests in the bond markets of different countries. Acharya and Pedersen (2005) show that the pricing equations of a CAPM derived in a frictionless economy but expressed in net returns, i.e. returns minus some arbitrary idiosyncratic premium, are equivalent to those derived from a CAPM where frictions are explicitly incorporated. Thus we can allow for impediments and imperfections on the local bond markets simply by rewriting an ICAPM for net returns. The standard ICAPM is then obtained if the idiosyncratic premia equal zero. In the paper we assume that impediments and imperfections in the local bond markets (i.e. market-specific transaction costs and taxation) disappear gradually over time. In particular, the idiosyncratic premia in the returns of government bonds over a riskfree rate converge to zero asymptotically so that, in the limit, the standard asset pricing equations hold. Acharya and Pedersen's equivalence result thus allows us to nest a standard ICAPM into an ICAPM with market imperfections and to assume that the latter gradually converges to the former. 
Methodologically, we use a linear state space approach to estimate the latent factor decomposition of the excess returns or risk premia that is implied by the theoretical model. In particular, we use weekly data over the period 1995-2006 to decompose the government bond risk premia of Belgium, France, Germany, Italy, and the Netherlands into a common component and an idiosyncratic component. ${ }^{1}$

The country-specific time-varying impacts of the common factor on the bond spreads, the "betas" (i.e. the ratios of the conditional covariance of the common factor and the bond returns over the conditional variance of the common factor), are also estimated. Del Negro and Otrok (2006) provide a Bayesian method to estimate a dynamic factor model with time-varying loadings where the factor loadings are assumed to follow driftless random walks. The approach that we follow, while less general in nature, is better suited for a CAPM since it involves the direct parameterization of the conditional covariances and variances in the "betas". In other words, the time-varying loadings in our approach are not stochastic so that our model still fits into a standard linear state space framework. ${ }^{2}$

We then investigate whether the idiosyncratic components in the government bond risk premia have converged towards zero by multiplying the idiosyncratic components in the bond risk premia by convergence operators of the type suggested by Luginbuhl and Koopman (2004).

Our results suggest that our ICAPM with market imperfections converges to a standard ICAPM, i.e. the idiosyncratic components in the excess returns converge towards zero for all five countries implying that the efficiency of the euro area government bond markets under consideration has increased. By the end of the sample period the government bond markets considered are almost fully efficient, with the exception of Italy. The results imply a decrease in the relevance of market imperfections like illiquidity (in particular market-specific transaction costs) and taxation in the government bond markets of the euro area. We find that the reduction of the risk premia can be attributed to a decrease in local market imperfections rather than to a decrease in the country-specific exposure to international risk. We do not attribute the decrease in the idiosyncratic components solely to the introduction of the euro on $1 / 1 / 1999$ because, first, the existing literature argues that convergence most likely is part of a wider global phenomenon (see

\footnotetext{
${ }^{1}$ As such we avoid the use of proxies. The latter are often imperfectly capturing the common state. For instance, US risk proxies may be only a part of the common factor and, as Geyer et al. (2004) suggest, European factors also are part of the story.

${ }^{2}$ Our approach of dealing with conditional covariances in a state space framework is an extension of the state space models with time-varying conditional variances as studied by Harvey et al. (1992).
} 
e.g. Schulz and Wolff 2008) and, second, our results suggest that, with the exception of Italy, the decrease of the idiosyncratic components starts some time after the introduction of the euro.

The outline of the paper is as follows. Section 2 presents the theoretical model. In section 3 we present the empirical specification and the estimation method. We also discuss data issues. Results from the estimations are reported in section 4, while the final section concludes.

\section{The model.}

There is a representative international investor who maximizes expected utility by choosing a consumption path over an infinite lifetime. This investor invests in the government bond markets of $N$ different countries $(i=1, \ldots, N)$, in a risk-free asset $b$, and in an international portfolio $w$. The period $t+1$ returns of the bonds $i(\forall i)$, the risk-free asset $b$, and the portfolio $w$ are denoted by $R_{i t+1}$ $(\forall i), R_{b t+1}$, and $R_{w t+1}$. The variable $\alpha_{i t+1}(>0)$ reflects the cost of impediments and imperfections encountered on the bond market of country $i(\forall i)$. In particular, $\alpha_{i t+1}$ captures market-specific transaction costs and tax components in bond returns. We assume that $\lim _{t \rightarrow+\infty} \alpha_{i t+1}=0$, i.e. these costs converge to zero as time passes by. For the risk-free asset $b$ and for the portfolio $w$ we assume that these costs are zero, i.e. $\alpha_{w t+1}=\alpha_{b t+1}=0 .^{3}$ The period $t+1$ utility function for the international investor is denoted by $u\left(c_{t+1}\right)$ where $c_{t+1}$ is period $t+1$ real consumption of the investor. The subjective rate of time preference of the investor is captured by the discount factor $\rho$ (with $0<\rho<1$ ). The stochastic discount factor which drives the returns $R_{i t+1}(\forall i)$ and $R_{w t+1}$ is defined as $m_{t, t+1} \equiv \rho \frac{u^{\prime}\left(c_{t+1}\right)}{u^{\prime}\left(c_{t}\right)}$.

These assumptions lead to the following first-order conditions,

$$
\begin{gathered}
E_{t}\left[m_{t, t+1}\left(R_{i t+1}-\alpha_{i t+1}\right)\right]=1 \\
E_{t}\left[m_{t, t+1}\right] R_{b t+1}=1 \\
E_{t}\left[m_{t, t+1} R_{w t+1}\right]=1
\end{gathered}
$$

where $E_{t}$ is the expectations operator conditional on the period $t$ information set and where eq.(1) holds $\forall i$. All first-order conditions reflect the fact that, in the optimum, the investor is

\footnotetext{
${ }^{3}$ We thus assume that there is no common factor in the liquidity premium. See Acharya and Pedersen (2005) and Favero et al (2007) for evidence on this for respectively the US stock market and euro area bond markets.
} 
indifferent between consuming an amount of 1 at time $t$ or investing this amount into $i(\forall i), b$, or $w$ and consuming $\left(R_{i t+1}-\alpha_{i t+1}\right), R_{b t+1}$, or $R_{w t+1}$ at time $t+1$. The expected, discounted marginal utility of both decisions is equal. Since $\lim _{t \rightarrow+\infty} \alpha_{i t+1}=0$, eq.(1) converges asymptotically to the standard Euler equation. We thus nest a standard CAPM into a CAPM with market imperfections and we assume that the latter gradually converges to the former. This is possible because of Acharya and Pedersen's (2005) equivalence result which shows that the pricing equations of our CAPM derived for a frictionless economy with returns minus some arbitrary idiosyncratic premium $\alpha_{i t+1}$, are equivalent to those derived for a CAPM where frictions are explicitly incorporated.

In appendix $A$ we show that we can write,

$$
E_{t}\left[R_{i t+1}\right]-R_{b t+1}=E_{t}\left[\alpha_{i t+1}\right]+\beta_{i t+1}\left(E_{t}\left[R_{w t+1}\right]-R_{b t+1}\right)
$$

where $\beta_{i t+1}=\frac{\operatorname{cov}_{t}\left[R_{w t+1}, R_{i t+1}-\alpha_{i t+1}\right]}{V_{t}\left[R_{w t+1}\right]}$. This equation states that the expected excess return of bond $i$ over the risk-free asset's return depends on the expected costs of market imperfections on market $i$, on the expected excess return of the international portfolio $\left(R_{w t+1}-R_{b t+1}\right)$, and on $\beta_{i t+1}$ which reflects the conditional covariance of the country-specific net bond return and the return on the global portfolio.

We rewrite eq.(4) as,

$$
\widetilde{R}_{i t+1}=\alpha_{i t+1}+\beta_{i t+1} \widetilde{R}_{w t+1}+\varrho_{i t+1}
$$

where the " $\sim$ " over a variable denotes excess returns, i.e. $\widetilde{R}_{i t+1}=R_{i t+1}-R_{b t+1}$ and $\widetilde{R}_{w t+1}=$ $R_{w t+1}-R_{b t+1}$, where $\beta_{i t+1}=\frac{\operatorname{cov}_{t}\left[\widetilde{R}_{w t+1}, \widetilde{R}_{i t+1}-\alpha_{i t+1}\right]}{V_{t}\left[\widetilde{R}_{w t+1}\right]}$. The error term $\varrho_{i t+1}=\left(\widetilde{R}_{i t+1}-E_{t}\left[\widetilde{R}_{i t+1}\right]\right)-$ $\left(\alpha_{i t+1}-E_{t}\left[\alpha_{i t+1}\right]\right)-\beta_{i t+1}\left(\widetilde{R}_{w t+1}-E_{t}\left[\widetilde{R}_{w t+1}\right]\right)$ where $E_{t}\left[\varrho_{i t+1}\right]=0$. It is straightforward to show that $\operatorname{cov}_{t}\left(\widetilde{R}_{w t+1}, \varrho_{i t+1}\right)=0$, and $\operatorname{cov}_{t}\left(\alpha_{i t+1}, \varrho_{i t+1}\right)=0$. Hence $\varrho_{i t+1}$ can be interpreted as pure measurement error. Our estimations show that its variance is always small and insignificant so we will neglect it in what follows. ${ }^{4}$

The remainder of the paper deals with the identification and the estimation of $\alpha_{i t+1}, \widetilde{R}_{w t+1}$, and $\beta_{i t+1}$, and with the question of whether the variable $\alpha_{i t+1}$ has converged towards zero. If it has, the efficiency of the government bond market is said to have increased.

\footnotetext{
${ }^{4}$ The estimation results with measurement error are available from the authors upon request.
} 


\section{Empirical specification, data, and estimation method.}

\subsection{Empirical specification.}

We estimate the following system (where $i=1, \ldots, N)$,

$$
\begin{gathered}
\widetilde{R}_{i t+1}=\alpha_{i t+1}+\beta_{i t+1} \widetilde{R}_{w t+1} \\
\alpha_{i t+1}=\kappa_{i t+1} \mu_{i}+\pi_{i} \alpha_{i t}+\kappa_{i t+1} \varepsilon_{i t+1} \\
\beta_{i t+1}=\phi_{i t+1} \beta_{i t}+\chi_{i t+1} \\
\widetilde{R}_{w t+1}=\mu_{w}+\pi_{w} \widetilde{R}_{w t}+\varepsilon_{w t+1}
\end{gathered}
$$

The main variable of interest is $\alpha_{i t+1}$. In section 2 we assume that $\lim _{t \rightarrow+\infty} \alpha_{i t+1}=0$. We therefore model the idiosyncratic component $\alpha_{i t+1}$ as an $A R(1)$ process, i.e. $\bar{\alpha}_{i t+1}=\mu_{i}+$ $\pi_{i} \bar{\alpha}_{i t}+\varepsilon_{i t+1}$ with $0<\pi_{i}<1$, multiplied by a deterministic convergence operator $\kappa_{i t+1}$ where $\lim _{t \rightarrow+\infty} \kappa_{i t+1}=0$. Thus, $\alpha_{i t+1}=\bar{\alpha}_{i t+1} \kappa_{i t+1}$. We can write $\bar{\alpha}_{i t+1}=\mu_{i} /\left(1-\pi_{i} L\right)+\varepsilon_{i t+1} /\left(1-\pi_{i} L\right)$ where $L$ is the lag operator. Multiplication by $\kappa_{i t+1}$ then gives $\alpha_{i t+1}=\kappa_{i t+1} \mu_{i} /\left(1-\pi_{i} L\right)+$ $\kappa_{i t+1} \varepsilon_{i t+1} /\left(1-\pi_{i} L\right)$. On multiplication of both sides of the latter expression by $\left(1-\pi_{i} L\right)$ we obtain eq.(7). For $\kappa_{i t}$ we use the following specification (see Luginbuhl and Koopman 2004),

$$
\kappa_{i t}=\exp \left[\xi_{i}\left(t-\tau_{i}\right)\right] /\left(1+\exp \left[\xi_{i}\left(t-\tau_{i}\right)\right]\right)
$$

where $\xi_{i}<0$ is the rate of convergence. Since $\xi_{i}<0$ we have $\kappa_{i t}=0$ for $t \rightarrow+\infty$ and $\kappa_{i t}=1$ for $t \rightarrow-\infty$. In a sample of size $T$ the fact that $\xi_{i}<0$ implies that $\kappa_{i t} \approx 0$ for $t>>>\tau_{i}$ and that $\kappa_{i t} \approx 1$ for $t<<<\tau_{i}$. The parameter $\tau_{i}$ with $1<\tau_{i}<T$ determines the mid-point of the change. Note that the model implies that $\alpha_{i t+1}>0$. We do not impose this condition in the estimations. Instead, we impose the weaker condition $\mu_{i}>0$ (for $i=1, \ldots, N$ ) which is easy to implement. Imposing $\alpha_{i t+1}>0$ would necessitate the use of nonlinear state space techniques which would seriously complicate the empirical analysis with only limited impact on the results since our results show that the restriction $\alpha_{i t+1}>0$ is only violated sporadically.

The error term $\varepsilon_{i t+1}$ is white noise and is assumed to follow a $G A R C H(1,1)$ process,

$$
\varepsilon_{i t+1}=h_{i t+1}^{1 / 2} \nu_{i t+1}
$$

where $\nu_{i t+1} \sim i . i . d(0,1)$ and where

$$
h_{i t+1}=V_{t}\left[\varepsilon_{i t+1}\right]=\delta_{i}^{a}+\delta_{i}^{b} \varepsilon_{i t}^{2}+\delta_{i}^{c} h_{i t}
$$


with $\delta_{i}^{a}>0,0<\delta_{i}^{b}<1,0<\delta_{i}^{c}<1$, and $0<\delta_{i}^{b}+\delta_{i}^{c}<1$. Note that the unconditional variance of $\varepsilon_{i t+1}$ is given by $\delta_{i}^{a} /\left(1-\delta_{i}^{b}-\delta_{i}^{c}\right)$.

As can be seen in eq.(9) we assume that the common component $\widetilde{R}_{w t+1}$ follows an $A R(1)$ process with $0<\pi_{w}<1$ and where $\varepsilon_{w t+1}$ is white noise and follows a $\operatorname{GARCH}(1,1)$ process,

$$
\varepsilon_{w t+1}=h_{w t+1}^{1 / 2} \nu_{w t+1}
$$

where $\nu_{w t+1} \sim i . i . d(0,1)$ and where

$$
h_{w t+1}=V_{t}\left[\varepsilon_{w t+1}\right]=\delta_{w}^{a}+\delta_{w}^{b} \varepsilon_{w t}^{2}+\delta_{w}^{c} h_{w t}
$$

with $\delta_{w}^{a}>0,0<\delta_{w}^{b}<1,0<\delta_{w}^{c}<1$, and $0<\delta_{w}^{b}+\delta_{w}^{c}<1$. Note that the unconditional variance of $\varepsilon_{w t+1}$ is given by $\delta_{w}^{a} /\left(1-\delta_{w}^{b}-\delta_{w}^{c}\right)$.

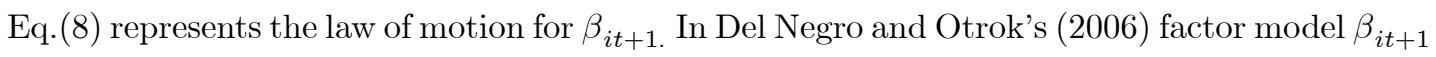
is assumed to follow a driftless random walk, i.e. $\phi_{i t+1}=1$ and $\chi_{i t+1}$ is white noise. The approach that we follow in this paper is based on a direct parameterization of the conditional covariance and variance in $\beta_{i t+1}$. Remember from section 2 that $\beta_{i t+1}=\frac{g_{i t+1}}{h_{w t+1}}=\frac{\operatorname{cov}_{t}\left[\widetilde{R}_{w t+1},\left(\widetilde{R}_{i t+1}-\alpha_{i t+1}\right)\right]}{V_{t}\left[\widetilde{R}_{w t+1}\right]}$. This can be written as $\beta_{i t+1}=\frac{g_{i t+1}}{h_{w t+1}}=\frac{\operatorname{cov}_{t}\left[\varepsilon_{w t+1}, \varepsilon_{i t+1}^{\prime}\right]}{V_{t}\left[\varepsilon_{w t+1}\right]}$ where $\varepsilon_{i t+1}^{\prime}=\varepsilon_{i t+1}^{R}-\kappa_{i t+1} \varepsilon_{i t+1}$ with $\varepsilon_{i t+1}^{R}=\widetilde{R}_{i t+1}-E_{t}\left[\widetilde{R}_{i t+1}\right]$ and $\kappa_{i t+1} \varepsilon_{i t+1}=\alpha_{i t+1}-E_{t}\left[\alpha_{i t+1}\right]$, and where $h_{w t+1}$ is given by eq.(14). We parameterize the conditional covariance $g_{i t+1}$ as a function of the lagged cross-product of the errors $\varepsilon_{w t+1}$ and $\varepsilon_{i t+1}^{\prime}$ and of its own lag (i.e. the diagonal bivariate $\operatorname{VEC}(1,1)$ of Bollerslev et al. 1988),

$$
g_{i t+1}=\gamma_{i}^{a}+\gamma_{i}^{b} \varepsilon_{w t} \varepsilon_{i t}^{\prime}+\gamma_{i}^{c} g_{i t}
$$

with $\gamma_{i}^{a}>0,0<\gamma_{i}^{b}<1,0<\gamma_{i}^{c}<1$, and $0<\gamma_{i}^{b}+\gamma_{i}^{c}<1$ for $i=1, \ldots, N$. Note that from eq.(6) we can write $\varepsilon_{i t+1}^{\prime}=\varepsilon_{i t+1}^{R}-\kappa_{i t+1} \varepsilon_{i t+1}=\beta_{i t+1} \varepsilon_{w t+1}$ so that eq.(15) can be rewritten as,

$$
g_{i t+1}=\gamma_{i}^{a}+\gamma_{i}^{b} \beta_{i t} \varepsilon_{w t}^{2}+\gamma_{i}^{c} g_{i t}
$$

Substituting eqs.(14) and (16) into $\beta_{i t+1}=\frac{g_{i t+1}}{h_{w t+1}}$ we obtain eq.(8) with $\phi_{i t+1}=\frac{\gamma_{i}^{b} \varepsilon_{w t}^{2}+\gamma_{i}^{c} h_{w t}}{h_{w t+1}}$ and $\chi_{i t+1}=\frac{\gamma_{i}^{a}}{h_{w t+1}}$ (where we have used $g_{i t}=\beta_{i t} h_{w t}$ ). Contrary to the specification for $\beta_{i t+1}$ considered by Del Negro and Otrok our specification for $\beta_{i t+1}$ can still be estimated in a linear state space framework with maximum likelihood. Our approach of dealing with conditional covariances in a state space framework is an extension of the state space models with time-varying conditional variances as studied by Harvey et al. (1992). 


\subsection{A look at the data.}

We calculate weekly holding period returns on government bonds for 5 countries: Belgium, France, Germany, Italy, and the Netherlands. As in many other studies bond returns are computed from the J.P. Morgan government bond indices (see e.g. Barr and Priestley 2004). ${ }^{5}$ An advantage of these indices is that the returns can be calculated in local currency (Belgian franc, French franc, German mark, Italian lira, Dutch guilder before 1/1/1999; euro afterwards). According to Ilmanen (1995) this is equivalent to analyzing currency hedged returns, i.e. a bond's local currency return can be considered a bond's currency hedged return for any foreign investor, independent of his home country. Local currency returns are relevant since we are interested in interest rate risk, not in exchange rate risk.

Since data are available on a daily basis we calculate the daily returns as the growth rate in the governmend bond index. We annualize the returns by multiplying by 260 (=number of trading days per year). We calculate the excess government bond returns or government bond risk premia by subtracting from the returns the risk free interest rate for which we use the 1 week eurocurrency rate provided by Financial Times/Intercapital (in local currency, annualized), and which is also available on a daily basis. The excess returns are in real terms because the inflation components in the government bond returns are cancelled out by the inflation components in the risk free rates (see Harvey 1991). This is in accordance with our theoretical model which holds for real returns. We then average the (annualized) daily excess returns to (annualized) weekly excess returns (monday to friday). Aggregation from daily to weekly data avoids the occurrence of day-of-the-week effects and averages out other noise while considerably reducing the computational time of our state space estimations.

The resulting dataset covers the period 06-01-1995 to 29-12-2006 providing 626 weekly observations per country. All data are taken from Datastream.

In table 1 we report the unconditional means and standard deviations of the annualized government bond excess returns of the 5 countries under investigation. First, we note that, irrespective of the sample period considered, the average excess returns are highest for Italy and lowest for

\footnotetext{
${ }^{5}$ We use the total return index over all maturities. Alternative indices with maturity bands $1-10$ or $7-10$ years are not available for all 5 countries for the period that we want to focus on (that is the period including the years before the introduction of the euro). An alternative method that we have considerered is to calculate returns from the zero coupon bond yield curves. Reliable data are available from BIS, but are again not available for the period that we want to focus on.
} 
Germany. For the full sample period the average annualized risk premium on government bonds of Italy is about 0.8 percentage points higher than the average annualized risk premium on German bonds. Second, for all countries, the average annualized excess return or risk premium in the first half of the sample (1995-2000) is considerably higher than in the second half of the sample (2001-2006). We test the significance of the mean excess return in each country and we find that it is significantly different from zero over the total period 1995-2006 and in the period 1995-2000 while the null hypothesis of a zero unconditional mean cannot unambiguously be rejected during the period 2001-2006.

In table 2 we report the unconditional correlations of the annualized government bond excess returns. First, the reported correlations clearly suggest that the excess returns are driven by a common component as our theoretical model predicts and as reported for instance by Ilmanen (1995). Second, we note that the correlation between the excess returns is considerably higher in the second half of the sample which indicates that the idiosyncratic components of the risk premia have become less relevant.

\subsection{Estimation.}

\subsubsection{Method.}

We obtain estimates for the unobserved states $\alpha_{i t+1}$ and $\widetilde{R}_{w t+1}$, for the conditional variance series $h_{i t+1}$ and $h_{w t+1}$, for the conditional covariance series $g_{i t+1}$ and thus for $\beta_{i t+1}$, for the convergence operator series $\kappa_{i t+1}$, and for the parameters in the model by putting the model described in section 3.1 in state space form. In particular, we estimate a Gaussian linear state space system including time-varying conditional variances (see Harvey et al. 1992 and Kim and Nelson 1999, chapter 6) and covariances. In Appendix B we report the state space representation of the model. Estimates of the state vector are obtained with the Kalman filter and smoother. Given the assumption of stationarity the initialization of the filter is non-diffuse.

The time-varying conditional variances and covariances complicate the otherwise standard state space framework. To deal with this we follow the approach by Harvey et al. (1992) and augment the state vector with the shocks $\varepsilon_{i t+1}$ and $\varepsilon_{w t+1}$. The Kalman filter then provides estimates of the conditional variance of the shocks, i.e. estimates for $h_{i t+1}$ and $h_{w t+1}$. This also allows us to calculate $g_{i t+1}$ and $\beta_{i t+1}$. We refer to appendix B for more details on the approach followed. 
To deal with potential computational difficulties that are caused by the relatively large dimension of the observation vector we follow the univariate approach to multivariate filtering and smoothing as presented by Koopman and Durbin (2000) and Durbin and Koopman (2001, chapter 6). A major advantage of this approach is that we can avoid taking the inverse of the variance matrix of the one-step-ahead prediction errors. We refer to Koopman and Durbin (2000) for the filtering and smoothing recursions and for the calculation of the likelihood.

\subsubsection{Identification.}

As is standard in factor models, first, to identify the factor loadings $\beta_{i t+1}$ we impose an unconditional variance of unity on $\varepsilon_{w t+1}$, i.e. $\sigma_{w}^{2}=1$. This amounts to setting $\delta_{w}^{a}=1-\delta_{w}^{b}-\delta_{w}^{c}$ (see Dungey et al. 2000). Second, implicitly factor loadings are also estimated on the states $\alpha_{i t+1}$ since eq.(6) can be written as $\widetilde{R}_{i t+1}=\kappa_{i t+1} \bar{\alpha}_{i t+1}+\beta_{i t+1} \widetilde{R}_{w t+1}$. We impose $\kappa_{i 1}=1(\forall i)$. Third, the sign of the factor loadings $\beta_{i t+1}$ cannot be identified because of the sign invariance of the factor variance decompositions of the spreads. Therefore, we impose $\beta_{i t+1}>0$. Since $\beta_{i t+1}=\frac{g_{i t+1}}{h_{w t+1}}$ we need $g_{i t+1}>0$ and $h_{w t+1}>0$. It is straightforward to show that under the processes and parameter restrictions discussed in section 3.1 these conditions hold. Fourth, our model contains constants (i.e. the data we use are not in deviations from the mean). Since we can only estimate $N$ constants but the model contains $N+1$ constants (i.e. $\mu_{w}$ and $\mu_{i}$ for $i=1, \ldots, N$ where $N=5$ ) we need to impose an identifying restriction on the constants. One possibility is to impose $\sum_{i=1}^{N} \mu_{i}=0$. We cannot impose this condition since we have implemented $\mu_{i}>0$ (for $i=1, \ldots, N$ ) to capture the non-negativity of $\alpha_{i t+1}$ (see section 3.1). Instead we impose $\mu_{w}=0$. We justify this by noting that in our data analysis in section 3.2 we find, for all countries, that the unconditional mean of the excess returns $\widetilde{R}_{i t+1}$ is not significantly different from zero in the second part of the sample while it is highly significant in the first part of the sample. Since $\beta_{i t+1}$ is strictly positive a value $\mu_{w}>0$ cannot lead to an unconditional mean of zero of the excess returns at any point in time. Therefore the restriction $\mu_{w}=0$ is sensible.

\section{Results.}

In table 3 we present the parameter estimates obtained from the estimation of the system given by eqs.(6) to (15). We also report a test for first-order autocorrelation in the one-step-ahead prediction errors of the system, i.e. a Ljung-Box test, and a goodness of fit test, i.e. the Akaike 
Information Criterion (AIC). These tests are discussed in Durbin and Koopman (2001, pages 34 and 152 respectively). In figures 1-12 we present different time series obtained from the estimation reported in table 3 .

From table 3 we note, first, that there are significant convergence effects since $\xi$ is significantly lower than zero for all countries. Also, according to a comparison of the AIC statistic for our model with convergence effects and the statistic calculated for the same model but without convergence effects (i.e. when setting $\kappa_{i t}=1 \forall i, t$ ), we find that the model with convergence effects is clearly preferred. In figures 1-5 the smoothed estimates for the idiosyncratic components $\alpha_{i t}$ are contrasted with the excess returns $\widetilde{R}_{i t}$. As can be seen from the figures the idiosyncratic components have decreased for all countries. By the end of 2006 the magnitude of $\alpha_{i t}$ is very close to zero for all countries with the exception of Italy. The estimated convergence operator series $\kappa_{i t}$ are reported in figure 7 and show the convergence of $\alpha_{i t}$ towards zero for all countries. It also shows that at the end of the sample period convergence has not been as radical for Italy as it has been for the other countries.

Second, the persistence in the conditional variance series $h_{i t}$ of the idiosyncratic component errors is very high as reflected by the sum $\delta_{i}^{b}+\delta_{i}^{c}$ which is close to 1 for all countries, i.e. we find integrated $G A R C H$ estimates for $h_{i t}$. From inspection of figures 8 and 9 we note that this is most likely due to the level shift in the variance of $\alpha_{i t}$ in all countries (see e.g. Lamoureux and Lastrapes). ${ }^{6}$ The conditional variance $h_{w t}$ for the common component $\widetilde{R}_{w t}$ is reported in figure 10. While it is rather persistent there is no integrated $G A R C H$ nor any indication of a structural break in this series. This is important for the estimated series for $\beta_{i t}$ which are approximated by dividing the estimated series for the conditional covariance $g_{i t}$ by the estimated series for $h_{w t}$. In figure 11 we report the conditional covariance series $g_{i t}$ for all countries. We find that $g_{i t}$ is constant for most of the sample period for all countries. In the first years of the sample there is some time-variation (i.e. a decline) in $g_{i t}$ for France and the Netherlands (as reflected also by an estimate for $\gamma_{i}^{b}$ that is significantly different from zero for these countries). As can be seen in figure 12 the impact of this time variation in $g_{i t}$ on the country-specific impacts $\beta_{i t}$ is very small however so that the movement in $\beta_{i t}$ is largely determined by $h_{w t}$ and is therefore very similar

\footnotetext{
${ }^{6}$ The finding of integrated GARCH may be due to the fact that $\kappa_{i t}$ seems to capture the decrease in the mean of $\alpha_{i t}$ (second half of sample) more than the decrease in the variance (first half of sample). Since Enders (2004, p140-141) argues that the finding of integraded GARCH causes no inference problems we do not try to alleviate this.
} 
across countries. In table 4 we report the estimation results of the system given by eqs.(6) to (15) but with a constant conditional covariance $g_{i t}$, i.e. $\gamma_{i}^{b}=\gamma_{i}^{c}=0$ for all $i$. From this table we note that our results are hardly affected by the imposed restrictions and that the AIC statistics reported in tables 3 and 4 are of equal magnitude (the time-varying $g_{i t}$ model is only slightly preferred). The magnitude of the estimated constant $g_{i t}=\gamma_{i}^{a}$ is highest for Italy and lowest for Germany, indicating that the impact of international risk on average is (slightly) higher for Italy. This provides some support for Codogno et al. (2003) who find that international risk factors are more important for the yields of Italian government bonds.

Our results thus suggest that it is $\alpha_{i t}$, rather than $\beta_{i t}$, that is responsible for the decrease in government bond excess returns in all countries. The reduction of the risk premia can be attributed to a decrease in illiquidity (in particular market-specific transaction costs) and taxation rather than to a decrease in the country-specific exposure to international risk. As far as liquidity is concerned this supports Bernoth et al. (2004) who argue that the introduction of the euro has decreased liquidity premia for euro area government bonds. Codogno et al. (2003) and Favero et al. (2007) find that, for the years 2002 and 2003, the liquidity component for government bonds is not very important.

It is tempting to attribute the decrease in the idiosyncratic components to the introduction of the euro on 1/1/1999. However, the convergence most likely is also part of a wider global phenomenon. Financial integration may also have accelerated because of more intense trade, improvements in information technology, and other technological and financial innovations (see e.g. Schulz and Wolff 2008). An indication for this in our results is that we estimate that the convergence te zero of $\alpha_{i t}$ starts rather late (see figure 7), quite some time after the introduction of the euro on $1 / 1 / 1999$. The exception here is Italy where the large decrease of the variance in $\alpha_{i t}$ in the nineties clearly affects $\kappa_{i t}$ before the introduction of the euro.

\section{Conclusions.}

In this paper we derive a model in which a standard international capital asset pricing model (ICAPM) is nested within an ICAPM with market imperfections. In the latter model an idiosyncratic stochastic factor affects the risk premium or excess return of government bonds on top of the systematic component that is common to all countries (and that is interacted with a time-varying 
idiosyncratic "beta"). We introduce asymptotic convergence from the full ICAPM with imperfections to the standard model by multiplying the idiosyncratic factor by convergence operators.

Methodologically, we use a linear state space approach to estimate the latent factor decomposition of the excess returns or risk premia that is implied by the theoretical model. In particular, we use weekly data over the period 1995-2006 to decompose the government bond excess returns of Belgium, France, Germany, Italy, and the Netherlands into a common component and an idiosyncratic component. The country-specific time-varying impacts of the common factor on the bond spreads, the "betas" (i.e. the ratios of the conditional covariance of the common factor and the risk premium over the conditional variance of the common factor), are also estimated. We investigate whether the idiosyncratic components in government bond excess returns have converged towards zero.

Our results suggest that the idiosyncratic components have converged towards zero for all five countries over the sample period: the variance and the mean of the idiosyncratic components are stronly reduced so that by the end of 2006 the idiosyncratic components are very close to zero in magnitude for all countries but Italy. Therefore, by the end of the sample period, the government bond markets of Belgium, France, Germany, and the Netherlands are almost fully efficient. Moreover, the reduction of the risk premia in all countries is attributed to a decrease in local market impediments and imperfections rather than to a decrease in the country-specific exposure to international risk.

\section{References}

Acharya, V., and L. Pedersen (2005): "Asset pricing with liquidity risk," Journal of Financial Economics, 77, 375-410.

Barr, D., and R. Priestley (2004): "Expected returns, risk and the integration of international bond markets," Journal of International Money and Finance, 23, 71-97.

Bernoth, K., J. von Hagen, and L. Schuknecht (2004): "Sovereign risk premia in the European government bond market," ECB Working Paper 369.

Bollerslev, T., R. Engle, and J. Wooldridge (1988): "A capital asset pricing model with time-varying covariances," Journal of Political Economy, 96(1), 116-131. 
Cappiello, L., R. Engle, and K. Sheppard (2003): "Asymmetric dynamics in the correlations of global equity and bond returns," ECB Working Paper 204.

Cochrane, J. (2005): Asset Pricing. Princeton University Press.

Codogno, L., C. Favero, and A. Missale (2003): "Yield spreads on EMU government bonds," Economic Policy, 18, 503-532.

Del Negro, M., and C. Otrok (2006): "Dynamic factor models with time-varying parameters," mimeo.

Dungey, M., V. Martin, and A. Pagan (2000): "A multivariate latent factor decomposition of international bond yield spreads," Journal of Applied Econometrics, 15, 697-715.

Durbin, J., And S. Koopman (2001): Time series analysis by state space methods, Oxford Statistical Science Series. Oxford University Press.

Enders, W. (2004): Applied Econometric Time Series. Wiley.

Favero, C., F. Giavazzi, and L. Spaventa (1997): "High yields: the spread on German interest rates," The Economic Journal, 107, 956-985.

Favero, C., M. Pagano, and E. von Thadden (2007): "How does liquidity affect government bond yields ?," CSEF Working Paper 181.

Geyer, A., S. Kossmeier, and S. Pichler (2004): "Measuring systematic risk in EMU government yield spreads," Review of Finance, 8, 171-197.

Hamilton, J. (1994): Time series analysis. Princeton University Press.

Harvey, A., E. Ruiz, and E. Sentana (1992): "Unobserved component time series models with ARCH disturbances," Journal of Econometrics, 52, 129-157.

Harvey, C. (1991): "The world price of covariance risk," Journal of Finance, XLVI(1), 111-157.

Ilmanen, A. (1995): "Time-varying expected returns in international bond markets," Journal of Finance, L(2), 481-506.

Kim, C., and C. Nelson (1999): State-space models with regime switching: classical and Gibbssampling approaches with applications. MIT Press. 
Koopman, S., And J. Durbin (2000): "Fast filtering and smoothing for multivariate state space models," Journal of Time Series Analysis, 21(3), 281-296.

Lamoureux, C., and W. Lastrapes (1990): "Persistence in variance, structural change, and the GARCH model," Journal of Business and Economic Statistics, 8, 225-234.

Luginbuhl, R., and S. Koopman (2004): "Convergence in European GDP series: a multivariate common converging trend-cycle decomposition," Journal of Applied Econometrics, 19, 611-636.

Schulz, A., And G. Wolff (2008): "Sovereign bond market integration: the euro, trading platforms and globalization," Deutsche Bundesbank Discussion Paper (Series 1) 12.

\section{Appendix A. Derivation of eq.(4).}

Write eq.(1) as,

$$
E_{t}\left[m_{t, t+1}\right] E_{t}\left[R_{i t+1}-\alpha_{i t+1}\right]+\operatorname{cov}_{t}\left(m_{t, t+1}, R_{i t+1}-\alpha_{i t+1}\right)=1
$$

From eq.(2) we have $E_{t}\left[m_{t, t+1}\right]=1 / R_{b t+1}$. By using this into eq.(A1) and re-arranging we obtain,

$$
E_{t}\left[R_{i t+1}\right]-R_{b t+1}=E_{t}\left[\alpha_{i t+1}\right]-\operatorname{cov}_{t}\left(m_{t, t+1}, R_{i t+1}-\alpha_{i t+1}\right) R_{b t+1}
$$

Since $\alpha_{w t+1}=0$ eq.(A2) written for $R_{w t+1}$ is,

$$
E_{t}\left[R_{w t+1}\right]-R_{b t+1}=-\operatorname{cov}_{t}\left(m_{t, t+1}, R_{w t+1}\right) R_{b t+1}
$$

(alternatively, use eq.(3) with $E_{t}\left[m_{t, t+1}\right]=1 / R_{b t+1}$ to obtain this).

Note that eq.(A2) can be rewritten as,

$$
\begin{aligned}
E_{t}\left[R_{i t+1}\right]-R_{b t+1}= & E_{t}\left[\alpha_{i t+1}\right] \\
& -\operatorname{cov}_{t}\left(m_{t, t+1}, R_{i t+1}-\alpha_{i t+1}\right) R_{b t+1} \frac{\operatorname{cov}_{t}\left(m_{t, t+1}, R_{w t+1}\right)}{\operatorname{cov}_{t}\left(m_{t, t+1}, R_{w t+1}\right)}
\end{aligned}
$$

By using eq.(A3) into this we obtain,

$$
\begin{aligned}
E_{t}\left[R_{i t+1}\right]-R_{b t+1}= & E_{t}\left[\alpha_{i t+1}\right] \\
& +\frac{\operatorname{cov}_{t}\left(m_{t, t+1}, R_{i t+1}-\alpha_{i t+1}\right)}{\operatorname{cov}_{t}\left(m_{t, t+1}, R_{w t+1}\right)}\left(E_{t}\left[R_{w t+1}\right]-R_{b t+1}\right)
\end{aligned}
$$


We assume that the returns $R_{i t+1}-\alpha_{i t+1}$ are driven by the stochastic discount factor $m_{t, t+1}$ as in the following equation,

$$
R_{i t+1}-\alpha_{i t+1}=\tau_{i t+1} m_{t, t+1}+u_{i t+1}
$$

where $u_{i t+1}$ is white noise and where $\tau_{i t+1}=\frac{\operatorname{cov}_{t}\left(m_{t, t+1}, R_{i t+1}-\alpha_{i t+1}\right)}{V_{t}\left[m_{t, t+1}\right]}$. This assumption implies that we impose causality running from the stochastic discount factor (i.e. consumption) to asset returns. We refer to Cochrane (2005, pages 37-41) for an enlightening discussion on this assumption and on why it can be justified. By averaging the RHS and LHS of eq.(A6) over $N$ international assets we can write,

$$
R_{w t+1}=\tau_{w t+1} m_{t, t+1}
$$

where $R_{w t+1}=N^{-1} \sum_{i=1}^{N} R_{i t+1}$ and $\tau_{w t+1}=N^{-1} \sum_{i=1}^{N} \tau_{i t+1}=\frac{\operatorname{cov}_{t}\left(m_{t, t+1}, R_{w t+1}\right)}{V_{t}\left[m_{t, t+1}\right]}$ and where we use the assumption $\alpha_{w t+1}=N^{-1} \sum_{i=1}^{N} \alpha_{i t+1}=0$ and $N^{-1} \sum_{i=1}^{N} u_{i t+1}=0$ to obtain the result.

Then note that,

$$
V_{t}\left[R_{w t+1}\right]=\tau_{w t+1} \operatorname{cov}_{t}\left(m_{t, t+1}, R_{w t+1}\right)
$$

and,

$$
\begin{aligned}
\operatorname{cov}_{t}\left(R_{i t+1}-\alpha_{i t+1}, R_{w t+1}\right) & =\tau_{i t+1} \tau_{w t+1} V_{t}\left[m_{t, t+1}\right] \\
& =\frac{\operatorname{cov}_{t}\left(m_{t, t+1}, R_{i t+1}-\alpha_{i t+1}\right)}{V_{t}\left[m_{t, t+1}\right]} \tau_{w t+1} V_{t}\left[m_{t, t+1}\right] \\
& =\operatorname{cov}_{t}\left(m_{t, t+1}, R_{i t+1}-\alpha_{i t+1}\right) \tau_{w t+1} \\
& =\frac{\operatorname{cov}_{t}\left(m_{t, t+1}, R_{i t+1}-\alpha_{i t+1}\right)}{\operatorname{cov}_{t}\left(m_{t, t+1}, R_{w t+1}\right)} V_{t}\left[R_{w t+1}\right]
\end{aligned}
$$

where the last line uses eq.(A8). This gives,

$$
\frac{\operatorname{cov}_{t}\left(m_{t, t+1}, R_{i t+1}-\alpha_{i t+1}\right)}{\operatorname{cov}_{t}\left(m_{t, t+1}, R_{w t+1}\right)}=\frac{\operatorname{cov}_{t}\left(R_{i t+1}-\alpha_{i t+1}, R_{w t+1}\right)}{V_{t}\left[R_{w t+1}\right]}=\beta_{i t+1}
$$

By substituting eq.(A9) into eq.(A5) we obtain eq.(4) in the text.

\section{Appendix B. State space representation of the model.}

The state space system with state vector $S_{t+1}$ is,

$$
\begin{gathered}
y_{t+1}=Z_{t+1} S_{t+1} \\
S_{t+1}=T_{t+1} S_{t}+K_{t+1} \eta_{t+1}
\end{gathered}
$$


with

$$
\begin{gathered}
\eta_{t+1 \mid t} \sim N\left(0, Q_{t+1}\right) \\
S_{1} \sim N\left(A_{1}, P_{1}\right)
\end{gathered}
$$

Since $N=5$ we have $y_{t+1}=\left[\begin{array}{lllll}\widetilde{R}_{1 t+1} & \widetilde{R}_{2 t+1} & \widetilde{R}_{3 t+1} & \widetilde{R}_{4 t+1} & \widetilde{R}_{5 t+1}\end{array}\right]^{\prime}$,

$S_{t+1}=\left[\begin{array}{lllllllllllll}1 & \alpha_{1 t+1} & \alpha_{2 t+1} & \alpha_{3 t+1} & \alpha_{4 t+1} & \alpha_{5 t+1} & \widetilde{R}_{w t+1} & \varepsilon_{1 t+1} & \varepsilon_{2 t+1} & \varepsilon_{3 t+1} & \varepsilon_{4 t+1} & \varepsilon_{5 t+1} & \varepsilon_{w t+1}\end{array}\right]^{\prime}$,

$\eta_{t+1}=\left[\begin{array}{llllll}\varepsilon_{w t+1} & \varepsilon_{1 t+1} & \varepsilon_{2 t+1} & \varepsilon_{3 t+1} & \varepsilon_{4 t+1} & \varepsilon_{5 t+1}\end{array}\right]^{\prime}$,

$A_{1}=\left[\begin{array}{lllllllllllll}1 & \frac{\mu_{1}}{1-\pi_{1}} & \frac{\mu_{2}}{1-\pi_{2}} & \frac{\mu_{3}}{1-\pi_{3}} & \frac{\mu_{4}}{1-\pi_{4}} & \frac{\mu_{5}}{1-\pi_{5}} & \frac{\mu_{w}}{1-\pi_{w}} & 0 & 0 & 0 & 0 & 0 & 0\end{array}\right]^{\prime}$

where $\mu_{w}=0$,

$\operatorname{diag}\left(P_{1}\right)=\left[\begin{array}{lllllllllllll}0 & \frac{\sigma_{\alpha 1}^{2}}{1-\pi_{1}^{2}} & \frac{\sigma_{\alpha 2}^{2}}{1-\pi_{2}^{2}} & \frac{\sigma_{\alpha 3}^{2}}{1-\pi_{3}^{2}} & \frac{\sigma_{\alpha 4}^{2}}{1-\pi_{4}^{2}} & \frac{\sigma_{\alpha 5}^{2}}{1-\pi_{5}^{2}} & \frac{\sigma_{w}^{2}}{1-\pi_{w}^{2}} & \sigma_{\alpha 1}^{2} & \sigma_{\alpha 2}^{2} & \sigma_{\alpha 3}^{2} & \sigma_{\alpha 4}^{2} & \sigma_{\alpha 5}^{2} & \sigma_{w}^{2}\end{array}\right]^{\prime}$

where $\sigma_{\alpha i}^{2}=\delta_{i}^{a} /\left(1-\delta_{i}^{b}-\delta_{i}^{c}\right)($ for $i=1, \ldots, 5)$ and $\sigma_{w}^{2}=\delta_{w}^{a} /\left(1-\delta_{w}^{b}-\delta_{w}^{c}\right)=1$,

$\operatorname{diag}\left(Q_{t+1}\right)=\left[\begin{array}{llllll}h_{w t+1} & h_{1 t+1} & h_{2 t+1} & h_{3 t+1} & h_{4 t+1} & h_{5 t+1}\end{array}\right]^{\prime}$

where $h_{i t+1}=\delta_{i}^{a}+\delta_{i}^{b} \varepsilon_{i t}^{2}+\delta_{i}^{c} h_{i t}($ for $i=1, \ldots, 5)$ and $h_{w t+1}=\delta_{w}^{a}+\delta_{w}^{b} \varepsilon_{w t}^{2}+\delta_{w}^{c} h_{w t}$ with $\delta_{w}^{a}=1-\delta_{w}^{b}-\delta_{w}^{c}$,

$$
Z_{t+1}=\left[\begin{array}{ccccccccccccc}
0 & 1 & 0 & 0 & 0 & 0 & \beta_{1 t+1} & 0 & 0 & 0 & 0 & 0 & 0 \\
0 & 0 & 1 & 0 & 0 & 0 & \beta_{2 t+1} & 0 & 0 & 0 & 0 & 0 & 0 \\
0 & 0 & 0 & 1 & 0 & 0 & \beta_{3 t+1} & 0 & 0 & 0 & 0 & 0 & 0 \\
0 & 0 & 0 & 0 & 1 & 0 & \beta_{4 t+1} & 0 & 0 & 0 & 0 & 0 & 0 \\
0 & 0 & 0 & 0 & 0 & 1 & \beta_{5 t+1} & 0 & 0 & 0 & 0 & 0 & 0
\end{array}\right]
$$

where $\beta_{i t+1}=\frac{g_{i t+1}}{h_{w t+1}}$ with $g_{i t+1}=\gamma_{i}^{a}+\gamma_{i}^{b} \beta_{i t} \varepsilon_{w t}^{2}+\gamma_{i}^{c} g_{i t}($ for $i=1, \ldots, 5)$,

$$
K_{t+1}=\left[\begin{array}{ccccccccccccc}
0 & 0 & 0 & 0 & 0 & 0 & 1 & 0 & 0 & 0 & 0 & 0 & 1 \\
0 & \kappa_{1 t+1} & 0 & 0 & 0 & 0 & 0 & 1 & 0 & 0 & 0 & 0 & 0 \\
0 & 0 & \kappa_{2 t+1} & 0 & 0 & 0 & 0 & 0 & 1 & 0 & 0 & 0 & 0 \\
0 & 0 & 0 & \kappa_{3 t+1} & 0 & 0 & 0 & 0 & 0 & 1 & 0 & 0 & 0 \\
0 & 0 & 0 & 0 & \kappa_{4 t+1} & 0 & 0 & 0 & 0 & 0 & 1 & 0 & 0 \\
0 & 0 & 0 & 0 & 0 & \kappa_{5 t+1} & 0 & 0 & 0 & 0 & 0 & 1 & 0
\end{array}\right]^{\prime}
$$




$$
T_{t+1}=\left[\begin{array}{ccccccccccccc}
1 & 0 & 0 & 0 & 0 & 0 & 0 & 0 & 0 & 0 & 0 & 0 & 0 \\
\mu_{1} \kappa_{1 t+1} & \pi_{1} & 0 & 0 & 0 & 0 & 0 & 0 & 0 & 0 & 0 & 0 & 0 \\
\mu_{2} \kappa_{2 t+1} & 0 & \pi_{2} & 0 & 0 & 0 & 0 & 0 & 0 & 0 & 0 & 0 & 0 \\
\mu_{3} \kappa_{3 t+1} & 0 & 0 & \pi_{3} & 0 & 0 & 0 & 0 & 0 & 0 & 0 & 0 & 0 \\
\mu_{4} \kappa_{4 t+1} & 0 & 0 & 0 & \pi_{4} & 0 & 0 & 0 & 0 & 0 & 0 & 0 & 0 \\
\mu_{5} \kappa_{5 t+1} & 0 & 0 & 0 & 0 & \pi_{5} & 0 & 0 & 0 & 0 & 0 & 0 & 0 \\
\mu_{w} & 0 & 0 & 0 & 0 & 0 & \pi_{w} & 0 & 0 & 0 & 0 & 0 & 0 \\
0 & 0 & 0 & 0 & 0 & 0 & 0 & 0 & 0 & 0 & 0 & 0 & 0 \\
0 & 0 & 0 & 0 & 0 & 0 & 0 & 0 & 0 & 0 & 0 & 0 & 0 \\
0 & 0 & 0 & 0 & 0 & 0 & 0 & 0 & 0 & 0 & 0 & 0 & 0 \\
0 & 0 & 0 & 0 & 0 & 0 & 0 & 0 & 0 & 0 & 0 & 0 & 0 \\
0 & 0 & 0 & 0 & 0 & 0 & 0 & 0 & 0 & 0 & 0 & 0 & 0 \\
0 & 0 & 0 & 0 & 0 & 0 & 0 & 0 & 0 & 0 & 0 & 0 & 0
\end{array}\right]
$$

where $\mu_{w}=0$ and where $\kappa_{i t+1}=\exp \left[\xi_{i}\left(t+1-\tau_{i}\right)\right] /\left(1+\exp \left[\xi_{i}\left(t+1-\tau_{i}\right)\right]\right)($ for $i=1, \ldots, 5)$. Note that $\kappa_{i 1}=1($ for $i=1, \ldots 5)$.

Some technical notes:

1. To apply the method proposed by Harvey et al. (1992) the conditional distribution of the error $\eta_{t+1}$ is assumed to be Gaussian. The unconditional distribution is of course not normal (see Hamilton 1994, p662).

2. Consistent estimation necessitates system matrices $Z_{t+1}, T_{t+1}, K_{t+1}$, and $Q_{t+1}$ that are either constant, exogenous or predetermined (see Hamilton 1994, chapter 13) which is the case in our model.

3. The filter is initialized with the matrices $A_{1}$ and $P_{1}$ which, given the assumption of stationary states, contain the unconditional means and variances of the states.

4. The time-varying conditional variances $h_{i t+1}$ and $h_{w t+1}$ complicate the linear Gaussian state space framework. To deal with this we follow the approach by Harvey et al. (1992) and we include the shocks $\varepsilon_{i t+1}$ and $\varepsilon_{w t+1}$ in the state vector. We note then that $h_{i t+1}($ for $i=1, \ldots, 5)$ and $h_{w t+1}$ and therefore $Q_{t+1}$ are functions of the unobserved states $\varepsilon_{i t}$ and $\varepsilon_{w t}$. Harvey et al. (1992) replace $h_{i t+1}$ and $h_{w t+1}$ in the system by $h_{i t+1}^{*}=\delta_{i}^{a}+\delta_{i}^{b} \varepsilon_{i t}^{* 2}+\delta_{i}^{c} h_{i t}^{*}$ and $h_{w t+1}^{*}=\delta_{w}^{a}+\delta_{w}^{b} \varepsilon_{w t}^{* 2}+\delta_{w}^{c} h_{w t}^{*}$ where the unobserved $\varepsilon_{i t}^{2}$ and $\varepsilon_{w t}^{2}$ are replaced by their conditional expectations $\varepsilon_{i t}^{* 2}=E_{t} \varepsilon_{i t}^{2}$ and $\varepsilon_{w t}^{* 2}=$ $E_{t} \varepsilon_{w t}^{2}$. Note that $E_{t} \varepsilon_{i t}^{2}=\left[E_{t} \varepsilon_{i t}\right]^{2}+\left[E_{t}\left(\varepsilon_{i t}-E_{t} \varepsilon_{i t}\right)^{2}\right]$ and $E_{t} \varepsilon_{w t}^{2}=\left[E_{t} \varepsilon_{w t}\right]^{2}+\left[E_{t}\left(\varepsilon_{w t}-E_{t} \varepsilon_{w t}\right)^{2}\right]$ 
where the quantities between square brackets are period $t$ Kalman filter output (conditional means and variances of the states $\varepsilon_{i t}$ and $\varepsilon_{w t}$ ). Thus, given $h_{i t}^{*}$ and $h_{w t}^{*}$ (which are initialized by the unconditional variances of $\varepsilon_{i t}$ and $\varepsilon_{w t}$, i.e. $\sigma_{\alpha i}^{2}$ and $\sigma_{w}^{2}$ ) and given the Kalman filter output from period $t$, namely $E_{t}\left(S_{t}\right)$ and $V_{t}\left(S_{t}\right)$, we can calculate $h_{i t+1}^{*}$ and $h_{w t+1}^{*}$ and the system matrix $Q_{t+1}$ which makes it possible to calculate $E_{t}\left(S_{t+1}\right), V_{t}\left(S_{t+1}\right)$ and $E_{t+1}\left(S_{t+1}\right), V_{t+1}\left(S_{t+1}\right)$, and so on...

5. The time-varying conditional covariances $g_{i t+1}$ and time-varying $\beta_{i t+1}$ further complicate the linear Gaussian state space framework. Note that $g_{i t+1}$ and $\beta_{i t+1}$ can be replaced by $g_{i t+1}^{*}=$ $\gamma_{i}^{a}+\gamma_{i}^{b} \beta_{i t}^{*} \varepsilon_{w t}^{* 2}+\gamma_{i}^{c} g_{i t}^{*}$ and $\beta_{i t+1}^{*}=\frac{g_{i t+1}^{*}}{h_{w t+1}^{*}}$ where $\varepsilon_{w t}^{* 2}$ and $h_{w t+1}^{*}$ are calculated as reported in 4 . The variable $h_{w t}^{*}$ is initialized by the unconditional variance of $\varepsilon_{w t}$, i.e. $\sigma_{w}^{2}$, while $g_{i t}^{*}$ is initialized by the unconditional covariance $\frac{\gamma_{i}^{a}}{1-\gamma_{i}^{b}-\gamma_{i}^{c}}$.

\section{Tables and Figures}


Table 1. Unconditional means and standard deviations of excess government bond returns.

\begin{tabular}{|c|c|c|c|c|c|}
\hline & Belgium & France & Germany & Italy & Netherlands \\
\hline & \multicolumn{5}{|c|}{ Full sample } \\
\hline & \multicolumn{5}{|c|}{$06-01-1995$ to 29-12-2006 } \\
\hline Mean & 0.0352 & 0.0324 & 0.0298 & 0.0379 & 0.0333 \\
\hline Standard deviation & 0.2488 & 0.2559 & 0.2402 & 0.2915 & 0.2467 \\
\hline Test & 0.0004 & 0.0016 & 0.0020 & 0.0012 & 0.0008 \\
\hline Mean & \multicolumn{5}{|c|}{ First half of sample } \\
\hline Standard deviation & 0.2510 & 0.2636 & 0.2360 & 0.3170 & 0.2556 \\
\hline Test & 0.0015 & 0.0045 & 0.0043 & 0.0062 & 0.0024 \\
\hline Test & 0.0732 & 0.1141 & 0.1261 & 0.0764 & 0.0980 \\
\hline
\end{tabular}

Note: Test reports the p-value of the test that the sample mean equals zero 
Table 2. Unconditional correlations of excess government bond returns.

\begin{tabular}{|c|c|c|c|c|c|}
\hline & Belgium & France & Germany & Italy & Netherlands \\
\hline & \multicolumn{5}{|c|}{ Full sample } \\
\hline & \multicolumn{5}{|c|}{ 06-01-1995 to $29-12-2006$} \\
\hline Belgium & 1 & - & - & - & - \\
\hline France & 0.9544 & 1 & - & - & - \\
\hline Germany & 0.9600 & 0.9334 & 1 & - & - \\
\hline Italy & 0.7903 & 0.8265 & 0.7627 & 1 & - \\
\hline \multirow[t]{3}{*}{ Netherlands } & 0.9630 & 0.9362 & 0.9792 & 0.7630 & 1 \\
\hline & \multicolumn{5}{|c|}{ First half of sample } \\
\hline & \multicolumn{5}{|c|}{ 06-01-1995 to $29-12-2000$} \\
\hline Belgium & 1 & - & - & - & - \\
\hline France & 0.9176 & 1 & - & - & - \\
\hline Germany & 0.9354 & 0.8809 & 1 & - & - \\
\hline Italy & 0.6373 & 0.7021 & 0.5844 & 1 & - \\
\hline \multirow[t]{3}{*}{ Netherlands } & 0.9375 & 0.8853 & 0.9700 & 0.5952 & 1 \\
\hline & \multicolumn{5}{|c|}{ Second half of sample } \\
\hline & \multicolumn{5}{|c|}{ 05-01-2001 to $29-12-2006$} \\
\hline Belgium & 1 & - & - & - & - \\
\hline France & 0.9946 & 1 & - & - & - \\
\hline Germany & 0.9847 & 0.9893 & 1 & - & - \\
\hline Italy & 0.9830 & 0.9886 & 0.9791 & 1 & - \\
\hline Netherlands & 0.9917 & 0.9943 & 0.9917 & 0.9821 & 1 \\
\hline
\end{tabular}


Table 3. Maximum likelihood estimation of the common factor model with GARCH errors and convergence effects (eqs. 6-15).

\begin{tabular}{|c|c|c|c|c|c|c|}
\hline & \multicolumn{5}{|c|}{ Country-specific parameters } & \multirow[t]{2}{*}{ Common parameters } \\
\hline & Belgium & France & Germany & Italy & Netherlands & \\
\hline \multirow[t]{2}{*}{$\mu$} & 0.0446 & 0.0433 & 0.0397 & 0.0460 & 0.0434 & - \\
\hline & $(0.0112)$ & $(0.0119)$ & $(0.0116)$ & $(0.0123)$ & $(0.0121)$ & - \\
\hline \multirow[t]{2}{*}{$\pi$} & -0.1429 & -0.1632 & -0.1924 & -0.1166 & -0.2145 & -0.0421 \\
\hline & $(0.0503)$ & $(0.0569)$ & $(0.0655)$ & $(0.0416)$ & $(0.0615)$ & $(0.0383)$ \\
\hline \multirow[t]{2}{*}{$\xi$} & -0.0204 & -0.0166 & -0.0204 & -0.0080 & -0.0178 & - \\
\hline & $(0.0033)$ & $(0.0032)$ & $(0.0039)$ & $(1.9 \mathrm{E}-6)$ & $(0.0033)$ & - \\
\hline \multirow[t]{2}{*}{$\tau$} & 552.23 & 562.89 & 571.50 & 625.99 & 570.25 & - \\
\hline & $(16.550)$ & $(22.546)$ & (16.119) & $(0.0024)$ & (18.464) & - \\
\hline \multirow[t]{2}{*}{$\delta^{a}$} & $9.8 \mathrm{E}-5$ & $1.6 \mathrm{E}-6$ & $1.4 \mathrm{E}-5$ & $6.0 \mathrm{E}-5$ & 0.0001 & $0.0863^{a}$ \\
\hline & $(2.8 \mathrm{E}-5)$ & $(1.0 \mathrm{E}-6)$ & $(5.2 \mathrm{E}-6)$ & $(2.8 \mathrm{E}-5)$ & $(2.9 \mathrm{E}-5)$ & $(0.0427)$ \\
\hline \multirow[t]{2}{*}{$\delta^{b}$} & 0.3724 & 0.1224 & 0.2069 & 0.1285 & 0.6522 & 0.0685 \\
\hline & $(0.0556)$ & $(0.0232)$ & $(0.0258)$ & $(0.0242)$ & $(0.1222)$ & $(0.0252)$ \\
\hline \multirow[t]{2}{*}{$\delta^{c}$} & 0.6223 & 0.8775 & 0.7924 & 0.8713 & 0.3386 & 0.8451 \\
\hline & $(0.0559)$ & $(0.0232)$ & $(0.0259)$ & $(0.0243)$ & $(0.1211)$ & $(0.0564)$ \\
\hline \multirow[t]{2}{*}{$\gamma^{a}$} & 0.0116 & 0.2440 & 0.2360 & 0.2479 & 0.0515 & - \\
\hline & $(0.0111)$ & $(0.0116)$ & $(0.0115)$ & $(0.0120)$ & $(0.0211)$ & - \\
\hline \multirow[t]{2}{*}{$\gamma^{b}$} & 0.0109 & 0.3879 & $5.5 \mathrm{E}-6$ & 0.0004 & 0.1286 & - \\
\hline & $(0.0177)$ & $(0.1781)$ & $(2.0 \mathrm{E}-5)$ & $(0.0009)$ & $(0.0630)$ & - \\
\hline \multirow[t]{2}{*}{$\gamma^{c}$} & 0.9510 & $5.9 \mathrm{E}-5$ & 0.0059 & 0.0009 & 0.7813 & - \\
\hline & $(0.0469)$ & $(0.0002)$ & $(0.0100)$ & $(0.0022)$ & $(0.0888)$ & - \\
\hline
\end{tabular}

Country-specific Ljung-Box test: no autocorrelation in the one-step-ahead prediction errors
pval
0.172
0.139
0.725
0.480
0.866

Full model: goodness of fit

$\begin{array}{lr}A I C^{c} & -13.9169 \\ A I C^{n} & -13.8562\end{array}$

Note: Hessian based standard errors between brackets. ${ }^{a}$ For the common state the estimate of $\delta^{a}$ is obtained from $\delta^{a}=1-\delta^{b}-\delta^{c}$. The Ljung-Box test uses lag length 1 (see Durbin and Koopman, 2001, p.34). AIC $C^{c}$ is Akaike Information Criterion for the model with convergence while $A I C^{n}$ is the criterion if no convergence, i.e. $\kappa_{i t}=1(\forall i, t)$. A model with a smaller $A I C$ is preferred (see Durbin and Koopman, 2001, p.152). 
Table 4. Maximum likelihood estimation of the common factor model with GARCH errors and convergence effects (eqs. 6-15) under the restriction of constant conditional covariances $g_{i t}=\gamma_{i}^{a}$ (i.e. $\left.\gamma_{i}^{b}=\gamma_{i}^{c}=0\right)$.

\begin{tabular}{|c|c|c|c|c|c|c|}
\hline & \multicolumn{5}{|c|}{ Country-specific parameters } & \multirow[t]{2}{*}{ Common parameters } \\
\hline & Belgium & France & Germany & Italy & Netherlands & \\
\hline \multirow[t]{2}{*}{$\mu$} & 0.0456 & 0.0448 & 0.0394 & 0.0481 & 0.0450 & - \\
\hline & $(0.0119)$ & $(0.0128)$ & $(0.0121)$ & $(0.0139)$ & $(0.0133)$ & - \\
\hline \multirow[t]{2}{*}{$\pi$} & -0.1451 & -0.1753 & -0.1521 & -0.1232 & -0.2315 & -0.0410 \\
\hline & $(0.0480)$ & $(0.0578)$ & $(0.0682)$ & $(0.0417)$ & $(0.0562)$ & $(0.0374)$ \\
\hline \multirow[t]{2}{*}{$\xi$} & -0.0201 & -0.0161 & -0.0198 & -0.0084 & -0.0169 & - \\
\hline & $(0.0032)$ & $(0.0032)$ & $(0.0039)$ & $(0.0007)$ & $(0.0033)$ & - \\
\hline \multirow[t]{2}{*}{$\tau$} & 550.05 & 559.31 & 568.77 & 596.66 & 564.36 & - \\
\hline & $(17.257)$ & $(26.304)$ & $(18.946)$ & $(3.8328)$ & $(22.235)$ & - \\
\hline \multirow[t]{2}{*}{$\delta^{a}$} & 0.0001 & $2.0 \mathrm{E}-6$ & $1.4 \mathrm{E}-5$ & $6.8 \mathrm{E}-5$ & $9.2 \mathrm{E}-5$ & $0.0915^{a}$ \\
\hline & $(3.0 \mathrm{E}-5)$ & $(1.3 \mathrm{E}-6)$ & $(5.4 \mathrm{E}-6)$ & $(3.2 \mathrm{E}-5)$ & $(2.4 \mathrm{E}-5)$ & $(0.0469)$ \\
\hline \multirow[t]{2}{*}{$\delta^{b}$} & 0.3826 & 0.1302 & 0.2019 & 0.1308 & 0.5765 & 0.0679 \\
\hline & $(0.0574)$ & $(0.0248)$ & $(0.0242)$ & $(0.0253)$ & $(0.1080)$ & $(0.0275)$ \\
\hline \multirow[t]{2}{*}{$\delta^{c}$} & 0.6132 & 0.8697 & 0.7973 & 0.8690 & 0.4177 & 0.8406 \\
\hline & $(0.0584)$ & $(0.0248)$ & $(0.0244)$ & $(0.0254)$ & $(0.1078)$ & $(0.0621)$ \\
\hline \multirow[t]{2}{*}{$\gamma^{a}$} & 0.2405 & 0.2470 & 0.2395 & 0.2513 & 0.2393 & - \\
\hline & $(0.0109)$ & $(0.0112)$ & $(0.0109)$ & $(0.0116)$ & $(0.0109)$ & - \\
\hline
\end{tabular}

Country-specific Ljung-Box test: no autocorrelation in the one-step-ahead prediction errors
pval
0.180
0.214
0.593
0.418
0.803

Full model: goodness of fit

$\begin{array}{lr}A I C^{c} & -13.9137 \\ A I C^{n} & -13.8498\end{array}$

Note: Hessian based standard errors between brackets. ${ }^{a}$ For the common state the estimate of $\delta^{a}$ is obtained from $\delta^{a}=1-\delta^{b}-\delta^{c}$. The Ljung-Box test uses lag length 1 (see Durbin and Koopman, 2001, p.34). $A I C^{c}$ is Akaike Information Criterion for the model with convergence while $A I C^{n}$ is the criterion if no convergence, i.e. $\kappa_{i t}=1(\forall i, t)$. A model with a smaller $A I C$ is preferred (see Durbin and Koopman, 2001, p.152). 
Figure 1: Risk premium and idiosyncratic state $\alpha_{i t}$ for Belgium

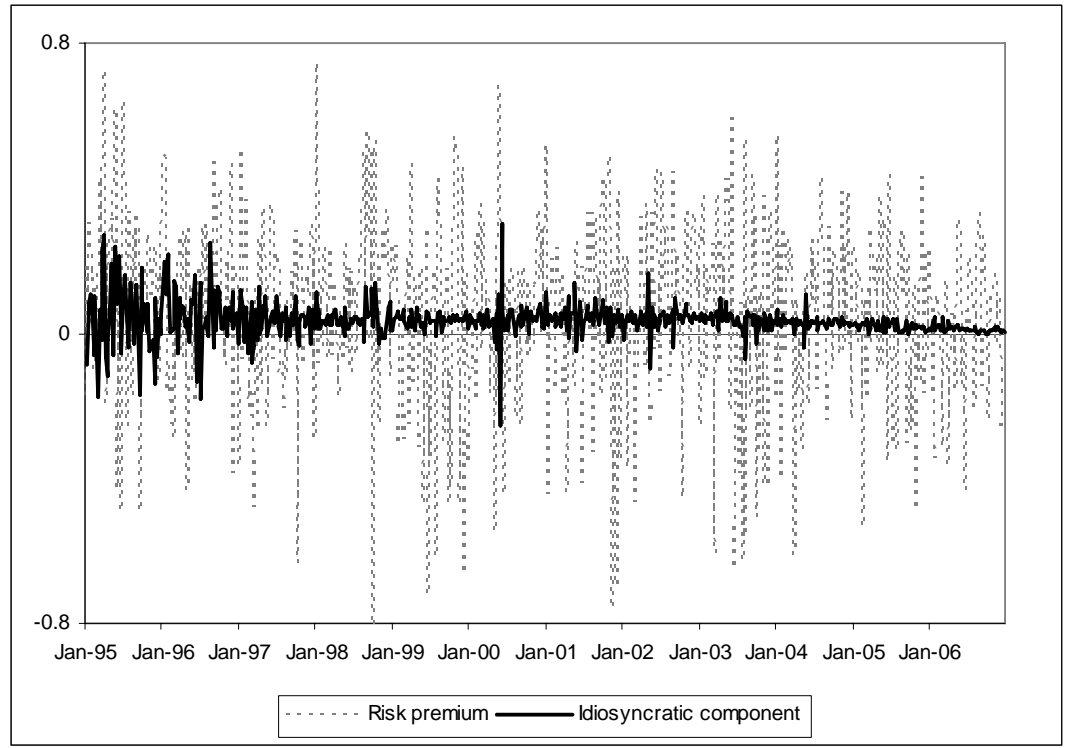

Figure 2: Risk premium and idiosyncratic state $\alpha_{i t}$ for France

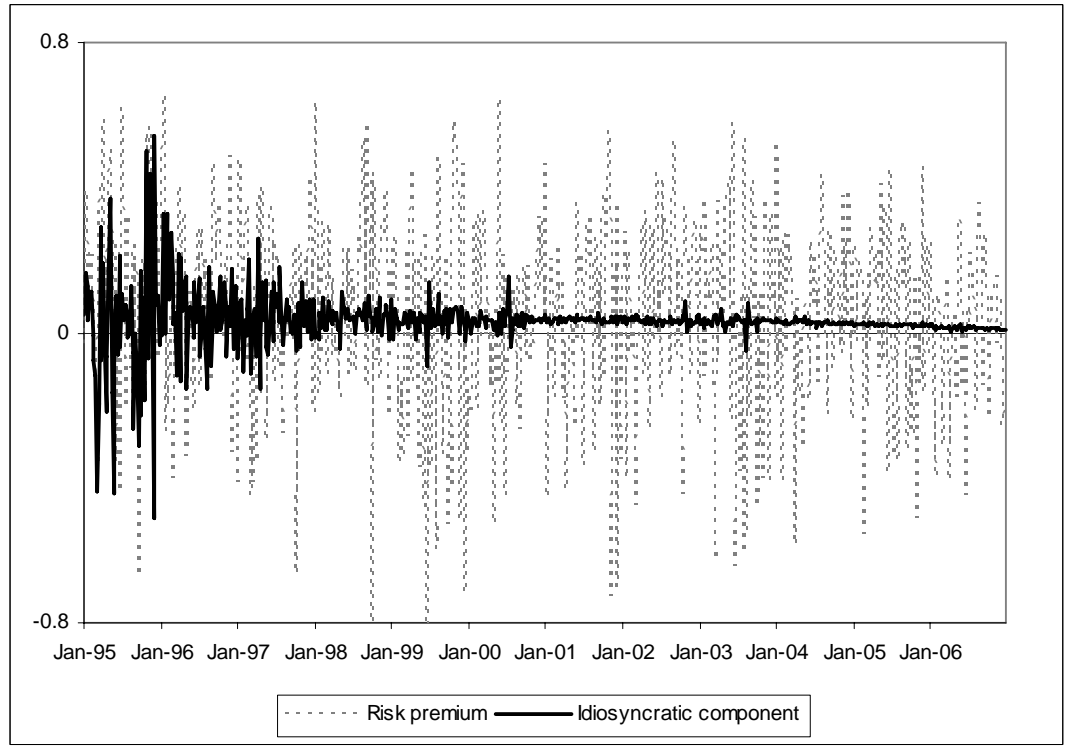


Figure 3: Risk premium and idiosyncratic state $\alpha_{i t}$ for Germany

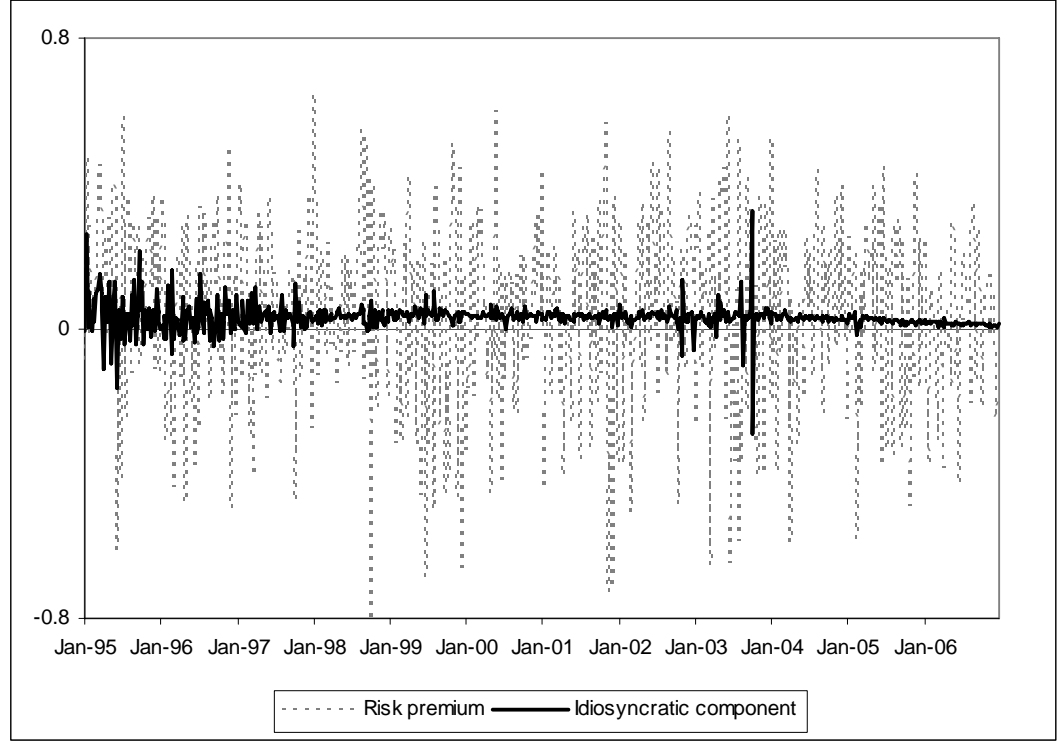

Figure 4: Risk premium and idiosyncratic state $\alpha_{i t}$ for Italy

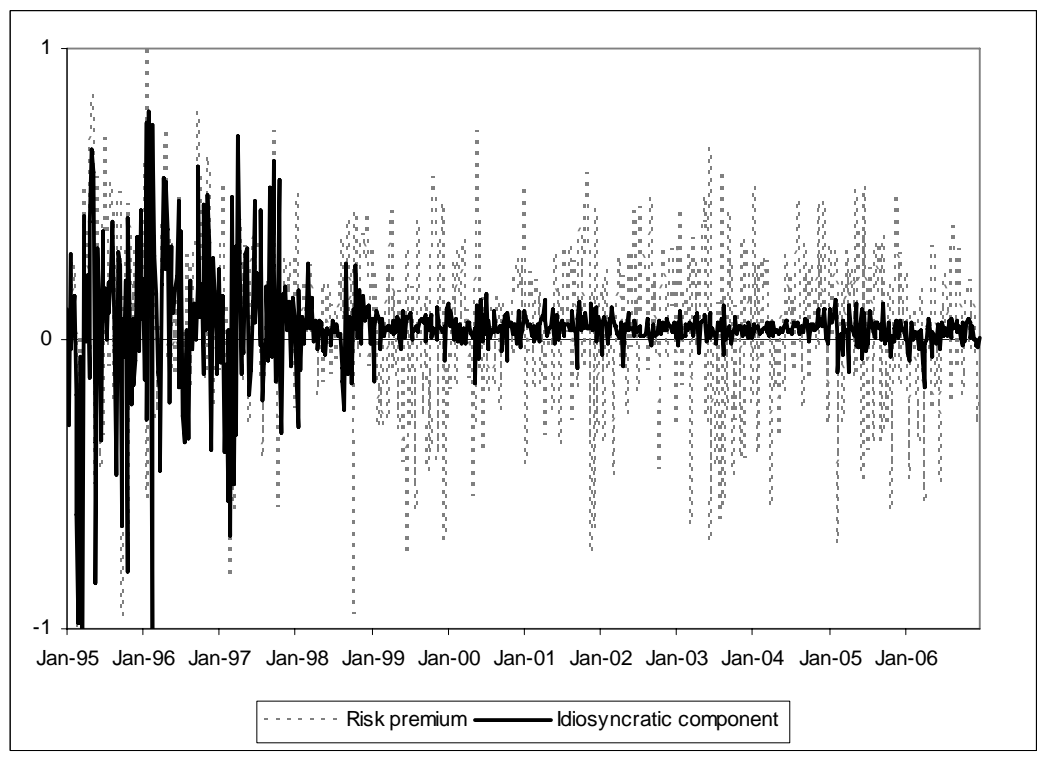


Figure 5: Risk premium and idiosyncratic state $\alpha_{i t}$ for the Netherlands

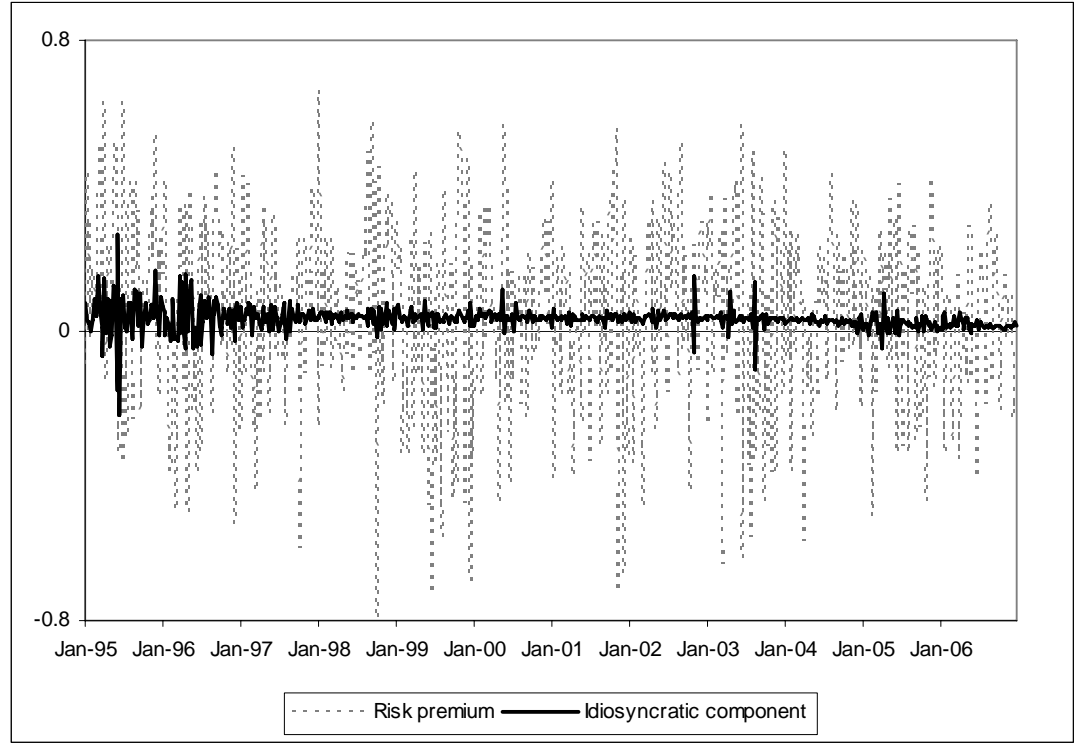

Figure 6: Common state $\widetilde{R}_{w t}$

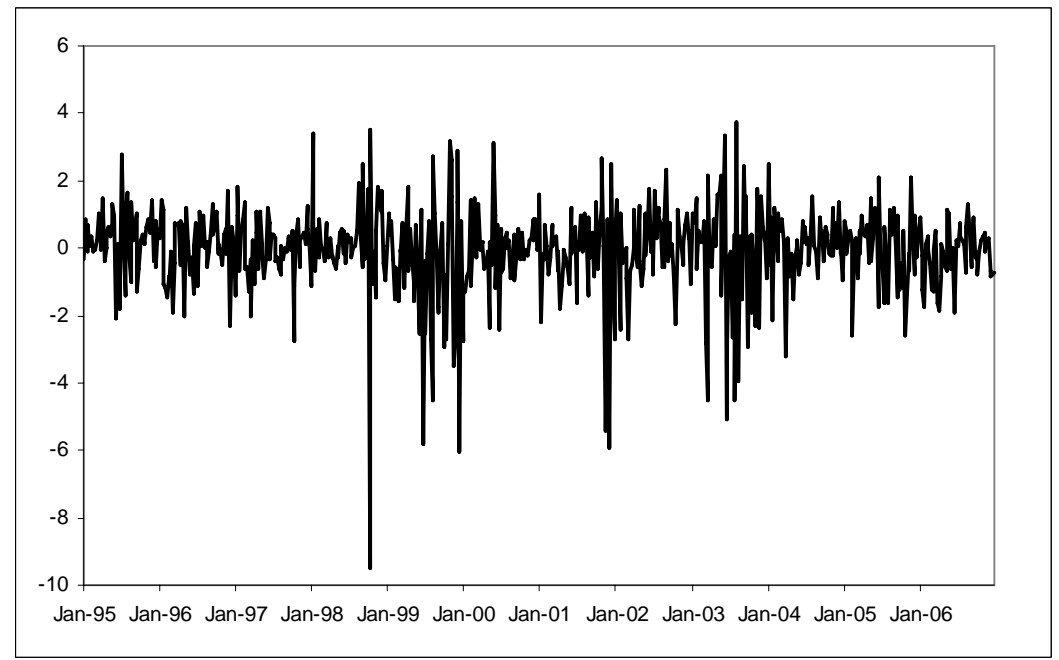


Figure 7: Convergence dynamics of the idiosyncratic states $\alpha_{i t}$ (convergence operators $\kappa_{i t}$ )

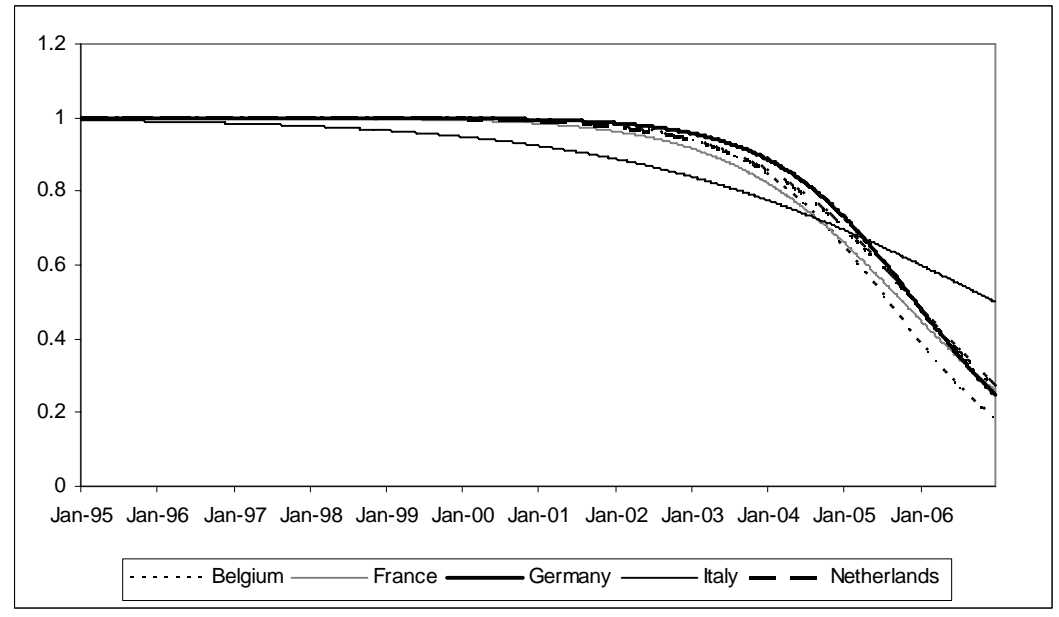

Figure 8: GARCH series $h_{i t}$ for Belgium, France, Germany, and the Netherlands

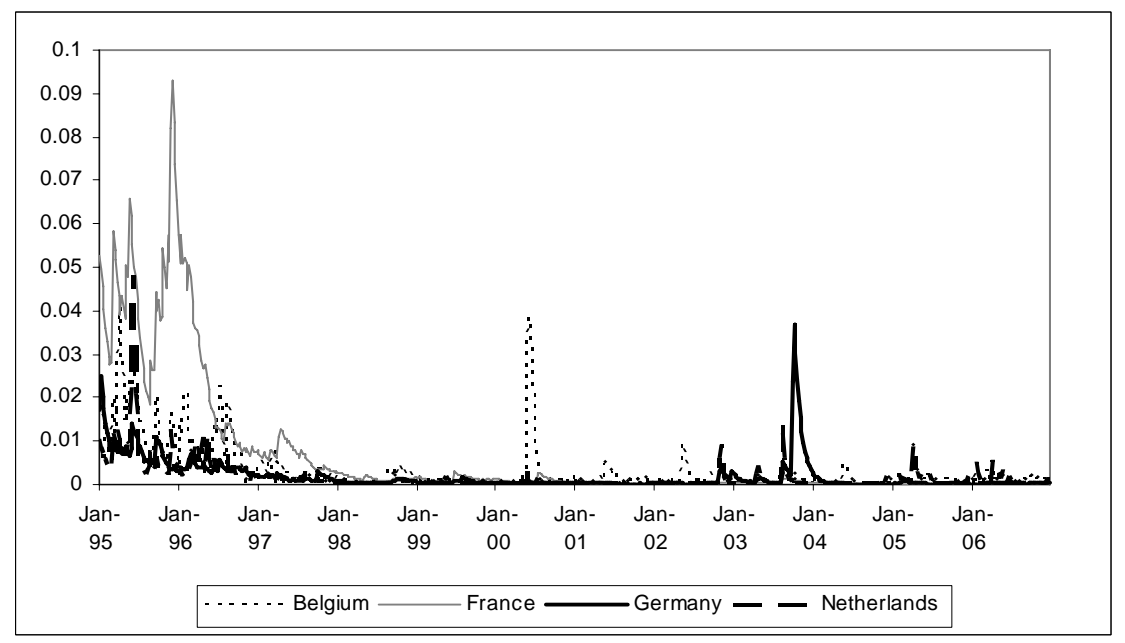


Figure 9: GARCH series $h_{i t}$ for Italy

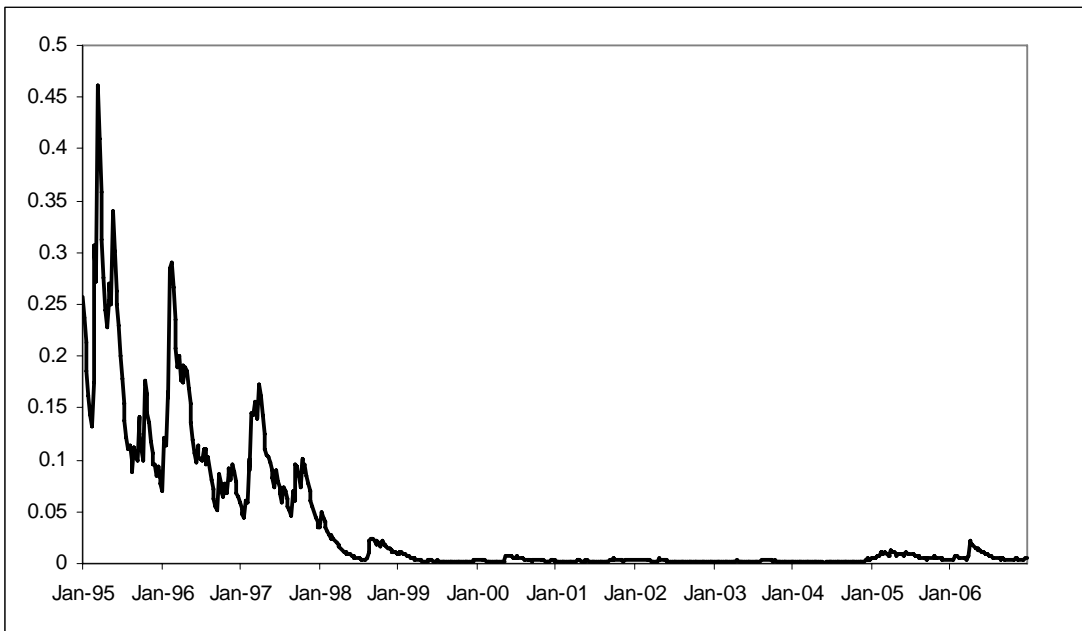

Figure 10: GARCH series $h_{w t}$ for the common state

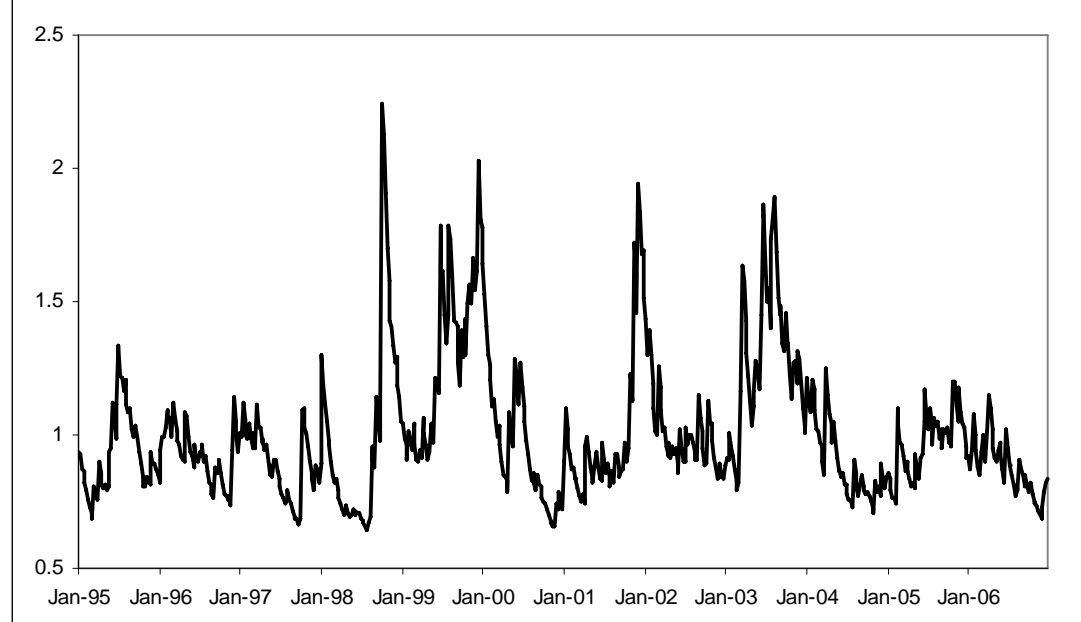


Figure 11: Conditional covariance series $g_{i t}$ for all countries

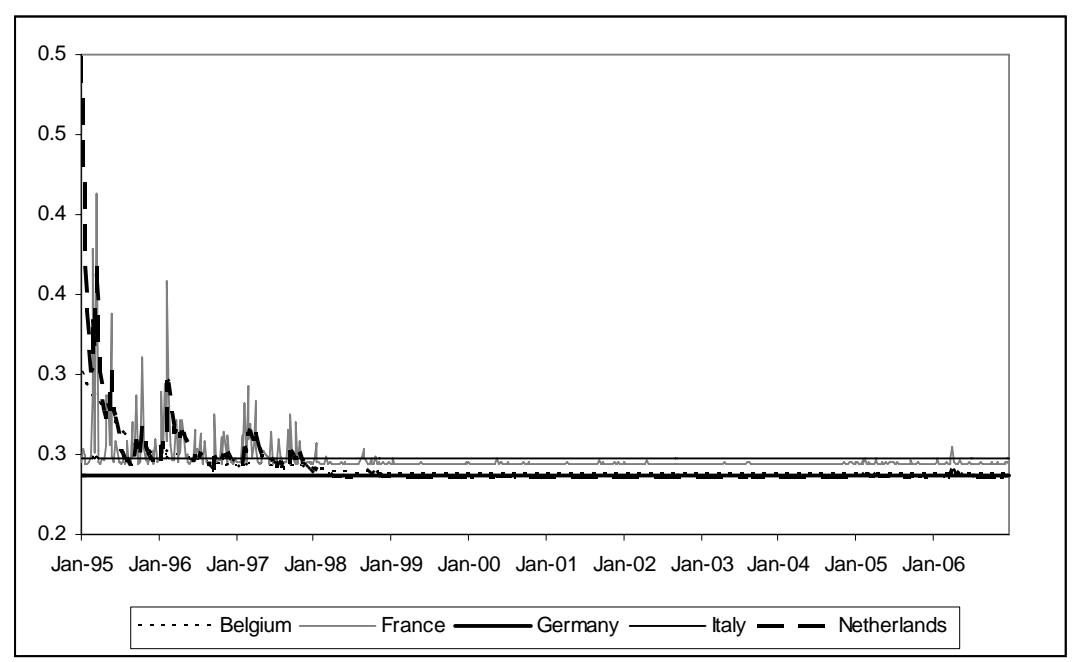

Figure 12: Time-varying $\beta_{i t}$ for all countries

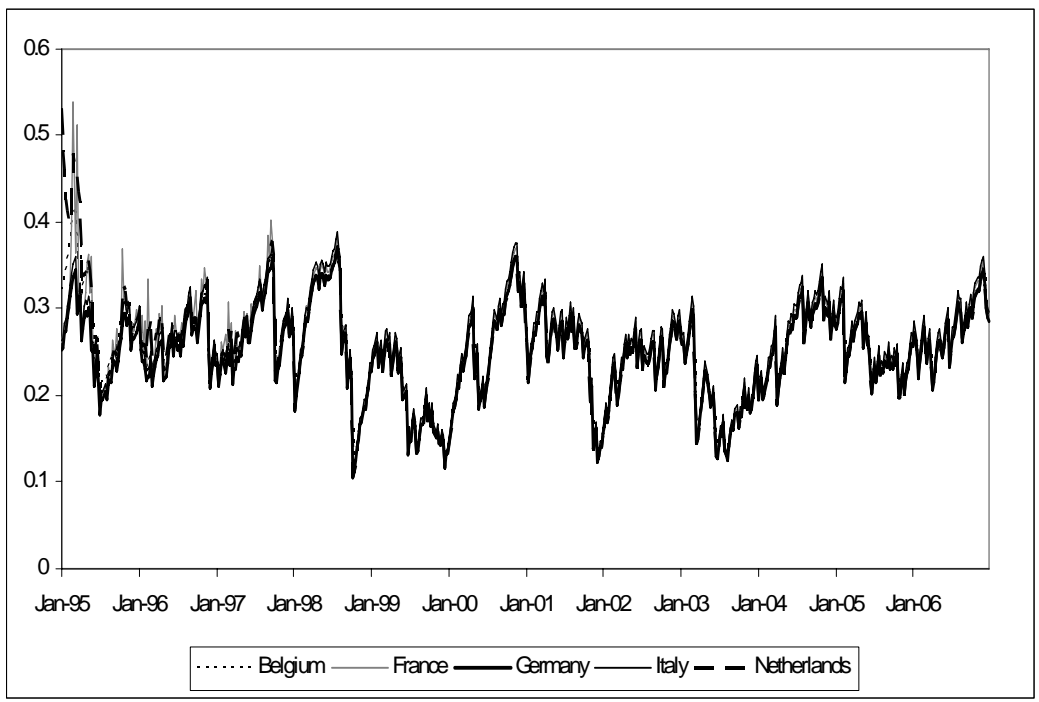

